\title{
Rapid Response Maintenance Based on Intelligent Early Warning Technology for Health Status of Aviation Equipment
}

\author{
Liming WANG ${ }^{1}$, Shuli YUAN ${ }^{2, *}$, Yang $\mathrm{LIU}^{1}$, Luqing SUN ${ }^{1}$, Lingzhi WANG ${ }^{1}$ \\ ${ }^{1}$ Qingdao Brunch of Naval Aeronautics University, Qingdao, China ; \\ ${ }^{2}$ Qindao Agricultural University, Qingdao, China \\ *Corresponding author. Email: qdyuansl@163.com
}

\begin{abstract}
On the basis of systematic research on the status quo of rapid response maintenance at home and abroad, this paper constructs a three-in-one MRO rapid response plan for aviation equipment, including fault prediction, early warning and maintenance by using modern information technology such as big data and artificial intelligence, through collecting the relevant data of aviation equipment maintenance support in an all-round way, according to the information collection and fusion of aviation equipment, health evaluation and fault prediction, MRO block chain system and the process of aviation MRO rapid response maintenance based on big data. The plan provides technical guidance for the military to carry out aviation equipment maintenance support.
\end{abstract}

Keywords: big data, aviation equipment, health status, intelligent early warning, rapid response maintenance.

\section{INTRODUCTION}

The central work of aviation equipment maintenance support is to keep the aviation equipment in good condition and ensure its reliability so as to be able to "run up and win" at any time, which requires that the aviation equipment maintenance support work be completed accurately, quickly and efficiently. With the continuous progress and development of new technology and methods, the modern equipment comprehensive support technology, which takes testing, diagnosis, maintenance, life prediction and health management as the main means, has attracted more and more attention at home and abroad. The needs of aviation equipment support is far different from the past, the former support needs is passive, need to implement passive maintenance and spare parts according to the equipment support plan, the current aviation equipment support is moving towards the direction of real-time monitoring and accurate positioning according to the health status, with the characteristics of active, intelligent and so on, therefore, This paper designs and validates an Repair equipment Maintenance-Repair-Operation system (MRO) predictive maintenance and maintenance block chain solution based on aviation big data in order to meet the operational mission and flight training needs under the information environment, improve the quality, efficiency and benefit of aviation equipment maintenance support, and improve the utilization rate of aviation equipment maintenance personnel and maintenance resources. It is of great significance to realize real-time monitoring, health management, risk warning, rapid response to maintenance and data merging, sharing and traceability of MRO service.

\section{CURRENT STATUS OF RAPID RESPONSE MAINTENANCE AT HOME AND ABROAD}

With the wide application of new technologies and methods, MRO predictive maintenance and block chain maintenance solutions strengthen the operation and maintenance of complex equipment based on health monitoring and management, real-time collection of aircraft status information, timely acquisition of aircraft health status, implementation of rapid response maintenance, greatly improving the efficiency of equipment quality management. 


\subsection{Application of Rapid Response Maintenance in Foreign Countries}

\subsubsection{GE and Honeywell}

GE and Honeywell have established MRO block chain systems for the maintenance of aircraft engines, cockpit and cabin electronics products manufactured and sold to international airlines, changing the way they record maintenance operations and replacing data currently in use. Spreadsheets and traditional paper logs can create unalterable digital records for each aircraft's planned and unscheduled maintenance activities. Operators will be able to know which technicians perform specific tasks against which aircraft during each maintenance interval. With block-chain technology, operators can track each component of each aircraft online, and get its complete history, current status, location, and maintenance records under high security authority.

\subsubsection{Spark Cognition Company}

Spark Cognition Company, which cooperates with the U.S. Air Force and Boeing for predictive maintenance, automatically builds a programmed model of an aircraft failure prediction system using machine learning technology. The first trial run shows that the system's failure prediction accuracy reached $70 \%-80 \%$.

\subsubsection{MMRO block chain project}

Recently, SITA announced the launch of the industry's first MMRO block chain project, whith is the first investigation project aimed at the air transport industry, together with key partners in the industry such as Bollor é Logistics, Cathay Pacific, FLYdocs, HAECO Group, Ramco Systems and SITA. It is reported that the project uses block chains to track, trace and document aircraft components, covering all aspects of the maintenance, repair and MRO chain, from parts manufacturing to maintenance to logistics and smart contracts. ${ }^{[1]}$

\subsection{Domestic Rapid Response Maintenance Application}

\subsubsection{Domestic civil aviation enterprises}

Has been committed to the study of advanced maintenance concepts, the application of big data technology in aircraft prediction and maintenance process. The International Aeronautical Engineering Department has established an aircraft status prediction and rapid maintenance response management platform with its own intellectual property rights based on big data; Southern Airlines has pioneered a cloud computing based "aircraft remote diagnosis and real-time system" to facilitate rapid and intelligent maintenance of aircraft; Hainan Airlines has created a big data application platform for aircraft health management, through realtime monitoring and health management of aircraft status, Discover hidden faults, abnormal operation events in time, optimize the maintenance and management level of aircraft fleet, effectively improve the safe operation quality and maintenance efficiency of aircraft fleet, and bring great convenience to the maintenance control, engineering management and maintenance department of airlines.

\subsubsection{Domestic aviation enterprises}

Aviation Industry Airborne Systems Company has carried out a lot of research in the application of on-board system diagnosis, prediction and health management engineering, avionics system in-flight test design, regional aircraft on-board maintenance software development, engine health diagnosis unit hardware architecture, aircraft structure Certain achievements have been made in the fields of health monitoring fiber Bragg grating sensing network and oil monitoring and sensing technology.

The Aviation Industry Measurement and Control Institute has completed the development of system-level products with fault diagnosis and health management technology as the core and the helicopter and aircraft airborne system as the main objects. Based on the key laboratory of aviation science and technology, it has carried out a lot of research on basic technology, common technology and key technology. In key technology research, the installation of a certain type of helicopter health and use system has achieved a domestic first, and it has taken the forefront in the field of engineering applications.

\section{DESIGN OF RAPID RESPONSE MAINTENANCE OF AVIATION EQUIPMENT}

With the deepening of the reform of military scale structure and strength and the large-scale assembly and high-frequency secondary use of aviation equipment, the quality information of the products throughout the whole life cycle of aviation equipment is more and more, including the design and manufacture standard information from the design and manufacture department, the production process information, the military flight and the daily maintenance information of aircraft, and the repair process information from the repair unit. Using big data technology to collect and analyze the quality information in the whole life cycle of aeronautical equipment, forecast the future trend of aeronautical equipment and make preventive measures according to the analysis results, which is helpful for the design and manufacture department to perfect or improve 
the design technology and process manufacturing method of aeronautical equipment, and help the military to monitor the change and development trend in the whole life cycle of aeronautical equipment. ${ }^{[2]}$ In order to improve the combat effectiveness of the military, it is also helpful for the repair unit to locate the fault quickly and accurately, and take preventive measures to improve the quality according to the development trend of aviation equipment.

\subsection{Health assessment and fault diagnosis of aviation equipment}

Through the aviation equipment maintenance preparation system, collect a large amount of maintenance work data, mission plan, maintenance personnel and other information obtained by various operation terminals of aviation equipment maintenance. such as failure, disassembly, replacement, modification, regular inspection, repair, overhaul, etc. , and carry out rapid and accurate fusion processing, storage, health evaluation and fault diagnosis of aviation equipment through the big data platform of aviation machinery service, In order to realize real-time monitoring, performance real-time evaluation, early warning of failure, effectively implement the quality control of the use and maintenance of aviation equipment, carry out the necessary maintenance tasks, understand the progress of handling the problems of aviation equipment, and provide a strong guarantee for the continuous combat effectiveness of the army. ${ }^{[3]}$

\subsection{Constructing Air Equipment Maintenance Data Link}

Through the establishment of maintenance data link, real-time sharing of recorded data among relevant operators through the special network, such as the monitoring of the intact condition of aviation equipment, the monitoring of the tactical technical $s$ indexes of airborne equipment, the monitoring of oil and liquid, and the early warning of real-time faults and the preparation of ship-to-surface aviation support, and through the asynchronous updating of maintenance blocks to realize timely data consolidation and storage, sharing and traceability, the ability of rapid response and unified coordination was improved, and the basis of automatic maintenance decision-making for data fusion analysis of all parties was formed. ${ }^{[4]}$

\subsection{Form a rapid response maintenance scheme for aviation equipment}

Under the support of the aforementioned on-line health management and equipment maintenance data link, the maintenance process Petri net model and resource scheduling algorithm are adopted to form the aviation equipment maintenance plan; and according to the measured results of human-computer interaction, the plan is confirmed and fine-tuned to form a quick response maintenance scheme for aviation equipment, which provides decision-making support for aviation equipment maintenance support units at all levels. ${ }^{[5]}$

\section{REALIZATION OF MAINTENANCE PROCESS FOR RAPID RESPONSE OF AVIATION EQUIPMENT}

Taking big data, cloud computing and artificial intelligence as technical support, starting from the safe operation and preventive maintenance of aviation equipment, the early warning of aviation equipment failure can be realized by real-time monitoring, intelligent diagnosis and fault prediction, and then the rapid response scheduling mode of aircraft MRO is established based on big data. The MRO block chain is designed according to the asynchronous update data of aircraft equipment maintenance, which can improve the maintenance efficiency and reduce the maintenance cost. The rapid response maintenance process for aviation equipment is shown in Figure 1.

\subsection{Acquisition and Fusion of Aviation Equipment Information}

Through the maintenance management system and quality control system of aviation equipment, the data of equipment data, flight data, maintenance data, training data and quality control data, flight parameter data, engine monitoring and oil analysis data are collected and combed. The application of advanced sensing technology and data mining technology to real-time monitoring and correlation analysis of flight data and quality characteristic data of important systems of aeronautical equipment has the capability of active sensing of operation state and fault identification of accessory module of aeronautical equipment.

\subsection{Health assessment and failure prediction of aviation equipment}

By comparing the health status data and maintenance history data of the system, the health evaluation model of aviation equipment based on data mining is used to evaluate the health status of aviation equipment, to recognize the early signs of the fault, and to diagnose and isolate the fault to judge the location, severity and development trend of the fault. A state prediction model based on neural network is constructed, which uses all kinds of data information such as flight parameters, usage status, current environment and working conditions, earlier test data, historical experience, etc. to realize the prediction of all aspects, such as failure, system safety, residual life, reliability, maintenance, service procurement, etc. ${ }^{[6]}$ 


\begin{tabular}{|c|c|c|}
\hline & $\begin{array}{c}\text { Health assessment and failure } \\
\text { prediction system }\end{array}$ & \\
\hline $\begin{array}{c}\text { Information Collection } \\
\text { and Fusion }\end{array}$ & $\begin{array}{l}\text { Aircraft carrier health assessment } \\
\text { model }\end{array}$ & $\begin{array}{l}\text { Response Scheduling } \\
\text { Based on Big Data }\end{array}$ \\
\hline $\begin{array}{c}\text { Aviation maintenance } \\
\text { management system } \\
\text { Equipment data } \\
\text { Flight data } \\
\text { Maintenance data } \\
\text { Training data } \\
\text {...... }\end{array}$ & $\begin{array}{l}\text { Health assessment } \\
\text { Diagnostic model } \\
\text { Fault prediction } \\
\text { Risk early warning }\end{array}$ & $\begin{array}{c}\text { Intelligent Decision-making } \\
\text { and Rapid Response } \\
\text { Maintenance Scheduling } \\
\text { Model Based on Expert } \\
\text { System and Genetic Algorithm }\end{array}$ \\
\hline $\begin{array}{c}\text { Aeroengine Quality Control } \\
\text { System } \\
\text { Quality control data } \\
\text { Flight parameter data } \\
\text { Supervision data } \\
\text { Oil-liquid data } \\
\ldots \ldots .\end{array}$ & $\begin{array}{c}\text { MROchain } \\
\text { Overall system architecture } \\
\text { SBOM storage chain } \\
\text { Block structure }\end{array}$ & $\begin{array}{l}\text { Real-time Aircraft Monitoring } \\
\text { and Data Sharing } \\
\text { Algorithm Matching and } \\
\text { Component Calling } \\
\text { Maintenance Job Scheduling and } \\
\text { Collaboration }\end{array}$ \\
\hline
\end{tabular}

Big Data/ Cloud Computing/ Artificial Intelligence

Figure 1 rapid response maintenance process for aviation equipment

\subsection{MRO block chain system for aviation equipment}

A materials model of XBOM (X-bill of equipment) mapping for aviation equipment is established to realize the fast response Service of multi-scene and multidemand, to ensure the consistency of the structural data of aviation equipment module and its MRO service data; then, the SBOM (Service BOM) storage chain is designed according to the use record and maintenance service of aviation equipment and non-on-line condition, to meet the need of incremental data merging and asynchronous update, MRO service traceability requirements. ${ }^{[7]}$

\subsection{Air MRO Rapid Response Scheduling Based on Big Data}

According to the data of condition monitoring, health evaluation and fault prediction of aviation equipment, through intelligent decision-making and quick response maintenance scheduling model based on expert system and genetic algorithm, some suggestions such as replacement and maintenance activities are made, so that the early warning can be issued before the failure of the monitored system, and the optimal maintenance scheme can be produced. At the same time, the process of maintenance support, the behaviour of maintenance support, the supply and dispatch of spare parts are managed effectively to improve the effectiveness, agility and coordination of maintenance support.

\section{CONCLUSION}

Comprehensive collection of aviation equipment maintenance support related data, with big data and artificial intelligence and other modern information technology to build a three-in-one aeronautical equipment MRO rapid response plan, to achieve data sharing among departments, improve the maintenance support personnel data analysis ability, mining the inherent law between the aeronautical machinery system data, To form a series of applicable application services, to realize the application innovation of fault factors analysis, fault correlation analysis, fault prediction, safety risk assessment and so on based on the big data of aviation machinery, to realize the functions of all kinds of maintenance information inquiry, search, statistics and so on, to provide technical guidance for the army to carry out the work of aviation equipment maintenance support, and to be able to automate, through data mining tools Intelligent in a large scale of aviation maintenance data to find the rules and characteristics of knowledge, for all levels of equipment support departments to provide decision-making support.

\section{REFERENCES}

[1] Alex Derber, Li Xuan. Aviation Maintenance and Engineering[J], 2020.03:9-10. 
[2] Yellow Blue, Wang Jinglin, Lin Zeli, Shen Yong. Key Technology and Research Path of Integrated System Health Management[J]. Aeronautical Science and Technology,2020,31 (07):12-17.

[3] Li Chunsheng, Zhang Lei, Zhang Lei. Current status of aircraft health real-time monitoring technology[J]. China Civil Aviation,2013 (10):6667.

[4] Li Quan, Zhou Xingshe. Research on spacecraft fault diagnosis technology based on TT \& C data mining $[\mathrm{J}]$. Computer Measurement and Control,2011,19 (3):500-503.

[5] Cao Xinxin, Yang Rong and Liu Ziyao. Research on Health Management Technology of Civil Aircraft[J]. Avionics Technology,2014.12 (4):1519.

[6] Hu Quqing, Hu Lei, Chen Ling, etc. J. Status, Future and Challenges of Equipment Health Management $[\mathrm{J}]$. Defense Science and Technology,2015,36 (1):10-15.

[7] Mo Guliang, Wang Huiyun, Li Xingang, et al. Development and Prospects of Aircraft Health Monitoring and Prediction System[J]. Vibration testing and diagnosis,2013,33 (6):925-930. 